http://dx.doi.org/10.4314/gjl.v7i2.3

\title{
THE SYNTAX OF RECIPROCAL CONSTRUCTIONS IN AKAN
}

\author{
Kofi K. Saah
}

\begin{abstract}
According to König and Gast (2008:2), "[R]eciprocity is not only of interest for linguists. Since this phenomenon lies at the root of social organization, it has fascinated philosophers, social scientists and biologists for many decades and even centuries." In this paper, I examine the kind(s) of construction(s) that are available to Akan speakers for the expression of reciprocal situations. The paper shows that reciprocal relations are expressed in Akan transitive constructions involving the use of: i) a reduplicated verb and a plural anaphor which is possessive pronoun plus ho "self"/ "body" construction (the same as what is used for reflexives), ii) an unduplicated verb and reduplicated anaphor, iii) a reduplicated verb and a reduplicated anaphor, and iv) a reduplicated verb and a plural anaphor plus the reduplicated quantifier nkorkor (Fa.)/ baako baako (Ak. \& As.).
\end{abstract}

Keywords: reciprocals, reciprocity, reflexives, anaphor(s), reduplication, quantifier

\section{Introduction ${ }^{1}$}

Reciprocal constructions and the issues of reciprocity have been studied for many years by linguists working on languages from the different language groups or families such as Gur (Swartz n.d.); Niger-Congo (Safir \& Selvanathan 2016); Australian (Evans et

\footnotetext{
${ }^{1}$ I would like to thank the audience at the Dolphyne @ 80 conference for their comments and suggestions on this paper. I would also like to thank Reginald Akuoko Duah for reading the manuscript and making some corrections. Of course, all imperfections are solely mine.
} 
al. 2007); Kavalan (Sung \& Sheng 2006); Igbo (Okeke 2008); Bantu (Maslova 2007); Japanese (Nishigauchi 2017); and many more ${ }^{2}$.

Reciprocity expresses the notion: " $X$ did something to/or perceived /felt something about $Y$ and $Y$ did the same thing to/about $X$." This refers to a situation where there are two or more people who are doing the same thing to one another. In this paper, I will explore the means by which Akan expresses reciprocal situations and the kind(s) of construction(s) used to achieve this purpose. Using attested data from the three literary dialects of Fante (Fa.), Akuapem (Ak.) and Asante (As.), I will discuss the similarities and differences, if any, in the reciprocal constructions in these three main Akan Twi dialects.

\subsection{Interpretation of Reciprocal Relations}

The interpretation of reciprocal constructions has been explored by many linguists. Evans et al. (2007: 541-542) give the semantic representations of examples like John and Mary kissed each other and John and Mary quarrelled with each other as follows:

(1) a. John and Mary kissed each other kiss $(\mathrm{j}, \mathrm{m}) \&$ kiss $(\mathrm{m}, \mathrm{j})$

b. John and Mary quarrelled with each other quarrel.with $(\mathrm{j}, \mathrm{m})$ \& quarrel.with $(\mathrm{m}, \mathrm{j})$. (Evans et al, 2007: 541-542, ex. 1)

Not being a semanticist, I will not attempt to give any sophisticated semantic representations of the examples I will use. I will rather give a simplified version like: $X \boldsymbol{V}$ $Y$ and $Y \boldsymbol{V} X$ (where $\mathrm{X}$ and $\mathrm{Y}$ are the participants and $\mathrm{V}$ is the verb). This characterization works perfectly where the reciprocal expression and its antecedent refer to single individuals. There are complications in the interpretation in situations where both the reciprocal and its antecedent refer to multiple participants, a problem which is beyond the scope of this paper.

\footnotetext{
${ }^{2}$ An anonymous reviewer asked me to be specific about the groups of Australian languages mentioned. Evans at al. (2007) mention about 21 languages and listing all of them here is not feasible. Maslova (2007) talks about Bantu in general, so I cannot be any more specific. In each of the works cited here, I have followed the names of languages and or groups of languages provided by the authors.
} 
The paper is divided into the following sections: Section 1 is the introduction. Section 2 explores the ways of expressing reciprocal situations in Akan, and Section 3 presents the summary and conclusion.

\section{Ways of Expressing Reciprocal Relations}

Languages differ in the way they encode reciprocal relations. According to Majid et al. (2011:1),

Linguists have long known that concepts of reciprocity are expressed in various ways through the structure of language: from lexicon ("feast," "exchange"), to special morphology in some languages, to full-blown grammatical constructions (e.g., "gave to each other," "shook one another's hands"). Indeed, many languages have grammatical constructions evolved specially for the purpose of expressing reciprocal actions and reciprocal states (e.g., "loved one another") ... In the case of reciprocity, many languages have constructions based on the nominal model, like English each other. Other languages, however, encode the same or a similar concept by means of a verbal affix. Most languages have more than one construction for expressing reciprocity.

Safir and Selvanathan (2016: 495) also state:

The prevailing idea about the typology of reciprocal constructions is that there are two major types: the constructions which encode reciprocity with a periphrastic anaphor and those that encode reciprocity within the verb itself (König \& Gast 2008, Siloni 2012, among others).

They show that in the examples, "The men hit each other" and "The men collided," the reciprocal meaning resides in the expression each other in the former while "the reciprocal meaning" in the latter "is lexicalized within the verb itself" (Safir \& Selvanathan ibid: 495-496).

The two strategies described by Safir and Selvanathan above are attested in Nzema a language closely related to Akan. Chinebuah (1976) shows that Nzema employs "reciprocal verbs" which "necessarily require a conjunction of noun phrases in subject 
position" and are used intransitively as in (2a) and other verbs that are used transitively together with "reciprocal complements" as in (2b) to express reciprocity:

(2) a. Kofi neé Akyz hón-le.

(Nzema)

Kofi and Akye fight.PST

'Kofi and Akye fought.'

(Chinebuah 1976:11, ex. 1a, interlinear glosses mine)

b. Kofi neé Akye zohó be nwó.

Kofi and Akye resemble.PRES.STAT 3PL.self

'Kofi and Akye resemble each other.'

(Chinebuah 1976:15, ex. 11a, interlinear glosses mine) $)^{3}$

It seems to me that the verb "fight" is inherently reciprocal. Since one cannot literally fight with him/herself, the sentence can only mean "Kofi fought with Akys and Akys fought with Kofi." In (2b) reciprocity is conveyed by the periphrastic anaphor be nwó "each other" which occurs as the complement/object of the verb zohó "resemble."

Akan has both strategies described for Nzema as the following examples show:

a. Kofi ne Ammako-e.

(Akan)

Kofi and Amma fight-PST

'Kofi and Amma fought (with each other).'

b. Kofi ne Amma se.

Kofi and Amma resemble.PRES.STAT

'Kofi and Amma resemble (each other).'

c. Kofi ne Amma tan won ho.

Kofi and Amma hate.PRES 3PL self

'Kofi and Amma hate each other.'

In these examples the notion of reciprocity is encoded in the intransitive verb in ( $3 a$ \& $b)$ and in the transitive verb and a periphrastic anaphor as in (3c).

It seems to me that a study of those verbs that are inherently reciprocal will yield very interesting results. For example, while ko "to fight" can only be used with a

\footnotetext{
${ }^{3}$ I wish to thank Emma Sarah Eshun for her help in glossing the Nzema examples.
} 
conjoined or plural NP to express reciprocity, others like se "resemble" can be used both transitively and intransitively for the same purpose. For example:

(4) a. Kofi ne Amma se.

Kofi and Amma resemble.PRES.STAT

'Kofi and Amma resemble (each other).'

b. Kofi se Amma.

Kofi resemble.PRES.STAT Amma

'Kofi resembles Amma (and by implication, Amma resembles Kofi)'

However, it is the (3c) type of construction in which a transitive verb and a periphrastic anaphora are used that I am interested in in this paper.

\subsection{Coding Reciprocal Relations in Akan}

Many languages of the world use polysemous anaphors for both reflexives and reciprocals. Otoo (2016:144) indicates that the same "possessive + he structure" is used for both reflexives and reciprocals in $\mathrm{Ga}$, another Kwa language spoken in Ghana. For example (5) may be ambiguous between a reciprocal and a reflexive interpretation in $\mathrm{Ga}$ :

Akwele ke Oko sums-s ame-he.

Akwele and Oko love-HAB 3PL-POS self

'Akwele and Oko love each other'

(Otoo 2016: 145, ex. 3e). ${ }^{4}$

Although Otoo translates this sentence as "Akwele and Oko love each other," (Sampson Korsah, personal communication) tells me that the sentence can also mean "Akwele and Oko love themselves."

Haspelmath (2013:354) reports that:

In the world's languages, identity with reflexives is not uncommon, but distinct reciprocal constructions are more common, especially in Eurasia. Outside of the Americas, identity of reciprocals and

\footnotetext{
${ }^{4}$ I wish to thank Sampson Korsah for his view on this sentence and confirming it by soliciting the views/judgements of other native speakers for me.
} 
reflexives is found especially in western and central Africa and Australia (Maslova \& Nedjalkov 2005).

Talking about specific West African languages, Safir and Selvanathan (2016:497) write:

The Gungbe and Fe'efe'e anaphors are two-way ambiguous between reciprocal and reflexive reading. The Yoruba anaphor ... even permits a literal interpretation 'their bodies'. Such polysemy is attested in several other African languages (many represented in the Afranaph database, including Babanki, Bafut, Ga, Ibibio, Limbum, Saari and Urhobo.

Akan is not an exception to this. Christaller (1875) writing about pronouns in Akan remarks:

When pronouns in the objective case are reflexives, they are compounded with the noun hõ = self : me hõ, ne hõ, yen hõ, mo

hõ, won hõ myself \& c. Odo ne hõ, he loves himself; yedo yen hõ, we love ourselves.

When the action expressed by the verb is reciprocal, either the compound form of the object pronoun, or only the last part of it, or the verb, is doubled:

Wodo won hõ-won hõ, or Wodo won hõ-hõ, or wododọ won hõ, they love each other.

Christaller's observations are borne out in this study. Akan marks reciprocal relations with a possessive pronoun + hõ construction which is the same structure as that used for reflexives. These forms function as the complements of transitive verbs which may or may not be reduplicated. As a result of this, there are situations where there is ambiguity between a reflexive reading and a reciprocal reading.

In the following sub-sections, I will outline the main strategies that Akan speakers use in reciprocal constructions. 


\subsubsection{Use of a Reduplicated Verb with a Plural Anaphor}

One method of expressing reciprocity is by reduplicating the verb and combining it with a periphrastic reflexive/reciprocal anaphor. Consider the following example:
Da bi ho no, na ${ }^{5}$ [wiram m-moa do-do
Day one there CD TSRM bush PL-animal love-REDUP.PST
won ho] sedee n-nipa binom
nso dodo won ho won ho
3PL self
as PL-person some
also love 3PL self 3PL self
yi ara.
DET.PART
also
'Once upon a time, all the animals in the bush loved one another just as some people also loved another.' (My translation).
(Ayeh 1978, p.37, English glosses and translation, mine.)

Concentrating on the bracketed clause in this extract, we see that the verb do "to love" has been reduplicated to dodo. It takes a plural subject wiram mmoa "bush animals" and selects a plural anaphor won ho "themselves" which is polysemous with the reflexive pronoun. The sentence could mean: "All the animals in the bush loved themselves" or "All the animals in the bush loved one another." Since the story is not about self-love, we can safely say that it is the reciprocal meaning that is intended.

The underlined section in this extract also contains a reciprocal construction of the kind that we will discuss in section 2.1.3. The strategy of using a reduplicated verb and plural anaphor is attested in all the three literary dialects of Akan as the examples in (7) show:

(7) a.
Na wo-so-ecr
anapahema, na [wo-dzi-i nsew
(Fa.)
and 3PL.wake up.PST early morning and 3PL.swear.PST oath

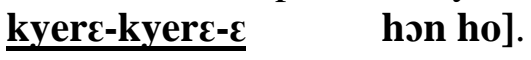
show.REDU.PST 3PL self
'Early the next morning, the men swore an oath to each other'
(Genesis 26:31 NIV).

\footnotetext{
${ }^{5}$ Some writers such as Boadi (2005) and Kandybowicz (2015) refer to this particle as a past tense marker. I disagree with this analysis. Following Clement (1982), I will refer to it as a temporal switch reference marker (TSRM). It is a means by which Akan speakers form complex tenses. This marker links the tense of the preceding clause/discourse with the tense/aspect of the following clause.
} 
b.

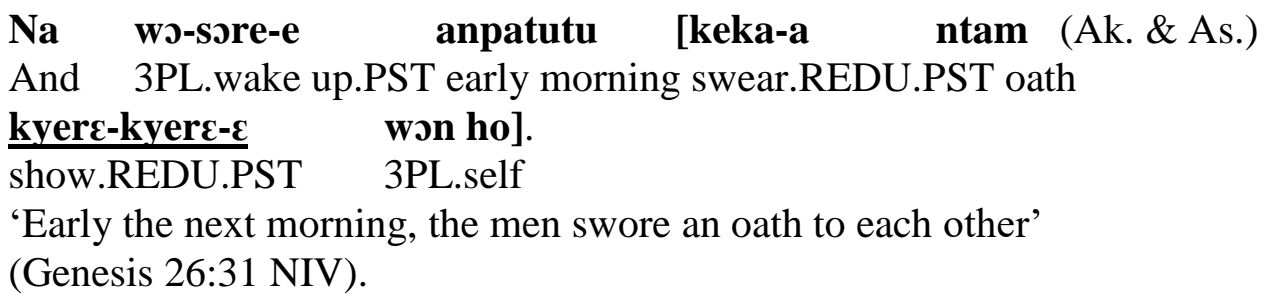

(8) a

\section{Nat homdze,}
And 2PL PL-sibling-PL 3PL.PERF.call 2PL PERF.give
adehyedzi na adehyedzi no m-ma o-n-n-y

freedom and freedom DEF NEG.let 3SG.INANM.NEG.be

kwan m-ma honam, na mbom

way NEG.give flesh but rather

[hom n-dua odo do n-son-som hom-ho.]

2PL SUBJUN.take love on SUBJUN.love.REDUP 2PL.self

'You, my brothers and sisters, were called to be free. But do not use your freedom to indulge the flesh; rather, serve one another humbly in love'

(Galatians 5:13, NIV).

b. A-nua-nom, adehyedi mu na wo-a-fre mo a-ba; (Ak. \& As) ${ }^{6}$ PL-sibling-PL freedom in that 3PL.PERF.call 2PL PERF.come

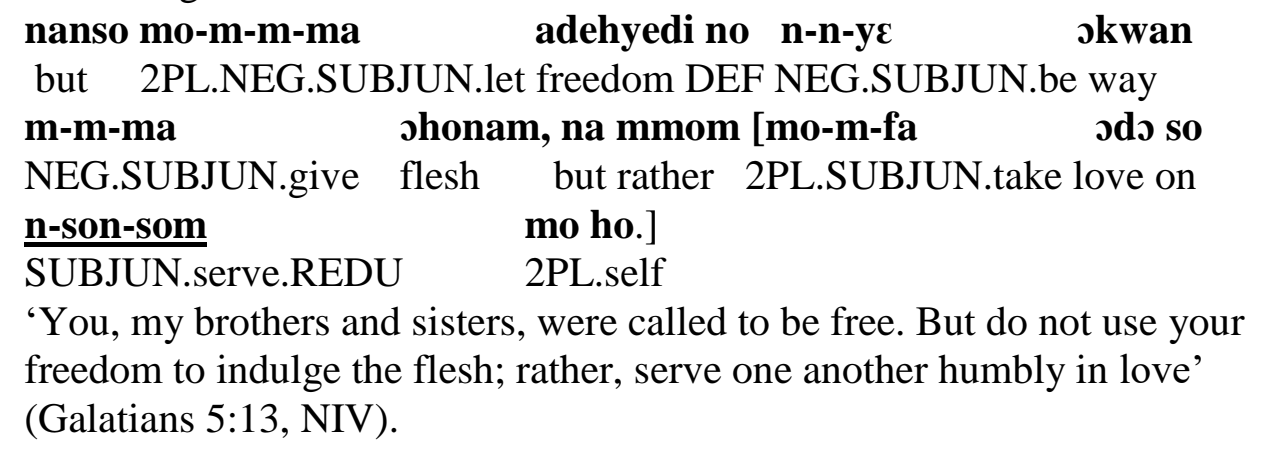

\footnotetext{
${ }^{6}$ In all the Akuapem and Asante translations, there were only minor differences reflecting the different pronunciations of certain words. The reciprocal is the same for both of them. As a result of this, I've used the Akuapem version to represent the two dialects in most cases to save space.
} 
The examples in (7) differ in one significant way. The Fante version in (7a) uses two conjoined sentences (They woke up early in the morning and they swore an oath to each other) while the Akuapem and Asante version uses a serial verb construction. Secondly, the Fante expression for "to swear an oath" is dzi nsew kyerc while the Twi (Akuapem and Asante) version is ka ntam kyere. The kyerc "show" part is reduplicated in both instances and it selects the plural periphrastic anaphor which is ambiguous between a reflexive reading and a reciprocal reading. The reduplicated verb signifies repeated action or multiple participants, and it seems to me, that the reciprocal interpretation is rather strong. ${ }^{7}$ The same is true of the examples in (8) in which both Fante and the Twi dialects reduplicate the verb som "to serve" which then selects a plural anaphor as its complement. Though a reflexive reading (serve yourselves) competes with a reciprocal reading (serve one another/each other), for one conversant with the Christian message, a reciprocal interpretation is more plausible. In other words, self-love is not what is being encouraged in these texts. This leads me to make the following general statement:

(9) A reciprocal situation is expressed by using a reduplicated verb which selects a plural periphrastic anaphor as its object/complement.

\subsubsection{Use of an Unreduplicated Verb and a Reduplicated Anaphor}

Another way of expressing a strong reciprocal situation is by using an unreduplicated verb which selects a reduplicated anaphor as its complement. Consider the following example:

\footnotetext{
${ }^{7}$ This is because, ordinarily, if a speaker wants to say that someone swore an oath, (a) is more felicitous than (b):

a. Kwame dzi-i nsew/ka-a ntam.

Kwame say-PST oath/say-PST oath

'Kwame swore an oath.'

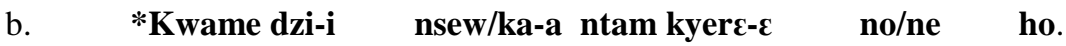
Kwame say.PST oath/say.PST oath show.PST 3SG.POSS self
} 

a. Ye-bo-s mpaes ma-a yen ho yen ho 1PL-say-PST prayer give-PST 1PL.POSS self 1PL.POSS self 'We prayed for each other.'
b. Ye-n-ya abotre m-ma yen ho yen ho. 1PL.SUBJUN.get patience SUBJUN.give 1PL.POSS self 1PL.POSS self 'Let's have patience for one another.'

In these examples, the underlined verbs are not reduplicated, but their anaphoric complements are. Without the reduplication of the anaphor, the sentence in (10a), for example, will be ambiguous: We prayed for ourselves (each person praying for him/herself) or We prayed for each other. But with the reduplication of the anaphor, the one plausible explanation is that every person said a prayer for every person in the group.

Initially, I did not have examples for this type of construction in the Fante data I had and I was tempted to think that Fante speakers do not utilize it. Patience Obeng (personal communication) not only confirmed that this option is available in Fante, but also provided me with the following examples:
a.
Hom n-sie
abotar m-ma
hom-ho
hom-ho (Fa.) 2PL SUBJUN.keep patience SUBJUN.give 2PL.POSS.self 2PL.POSS.self 'Have patience for one another.'
b. Hom n-kyen kom m-ma hom-ho hom-ho. 2PL SUBJUN fast SUBJUN.give 2PL.POSS.self 2PL.POSS.self 'Fast for one another/each other.'
c. Wo-kyir hon-ho hon-ho. 3PL.hate 3PL.POSS.self 3PL.POSS.self They hate each other/one another.'

In these examples, the verb is not reduplicated, but the anaphor is just as in the Twi examples in (10). It seems to me that the reduplicated plural anaphor in such constructions precludes a reflexive reading in these examples.

Based on these facts, we will make a second general statement as follows:

\footnotetext{
${ }^{8}$ I heard this example from Pastor Owusu Ansah on a radio programme in the morning of Tuesday $11^{\text {th }}$ July 2006.

${ }^{9} \mathrm{I}$ heard and noted this sentence also from a sermon I attended at a wedding at Anum on $29^{\text {th }}$ September

2018. The preacher was exhorting the couple and all present to be patient with one another.
} 
(12) A reciprocal situation is expressed by using an unreduplicated verb which selects a reduplicated anaphor as its object/complement.

\subsubsection{Use of a Reduplicated Verb and a Reduplicated Anaphor}

The following examples seem to suggest that the Twi dialects allow a construction in which both the verb and the anaphor are reduplicated, while Fante allows only the reduplication of the verb without the reduplication of the anaphor. Consider the following examples:

a. [Na wo-se-se-e

hon-ho] de, won-hwe

and 3PL.say.REDU.PST 3PL.self that 3PL.see

o-daasofo no na p-re-ba

no.

SG.dreamer DEF FM 3SG.PROG.come CD

'Here comes the dreamer!' 'They said to each other' (Genesis 37:19 NIV)

b. [Na wo-si-se-e won ho won ho] se: Hwe

and 3PL.say.REDU.PST 3PL self 3PL self that look

o-daesofo no na o-re-ba no.

SG.dreamer DEF FM 3SG.PROG.come CD

'Here comes the dreamer!' 'They said to each other' (Genesis 37:19 NIV)

c. [Na wo-se-se-e won ho won ho] se: Hwe

(As.)

and 3PL.say.REDU.PST 3PL self 3PL self that look

daesofos no na o-re-ba no.

SG.dreamer DEF FM 3SG-PROG-come CD

'Here comes the dreamer!' 'They said to each other' (Genesis 37:19 NIV)

(14) a. Na sc emi Kyerckyercfo nye Ewuradze, m-a-hohor hom (Fa.)

and if 1SG Teacher and Lord 1SG-PERF-wash 2PL.POSS

a-nan ho a, hom so sede [ hom hohor hom a-nan ho

PL.foot body COND 2PL also be.necessary 2PL wash 2PL.POSS

PL.foot body

n-korkor].

PL.one.REDU 
'If I then, your Lord and Teacher, have washed your feet, you also ought to wash one another's feet' (John 13:14, NIV).

b. Afei se me, Awurade ne Kyerckyercfo no, m-a-hohoro (Ak. \& As.) Now if $1 \mathrm{SG}$ Lord and Teacher DEF 1SG-PERF-wash

mo nan ho a, na $\varepsilon$-se $\quad$ se

2PL.POSS feet body COND then 3SG.INA.be necessary that mo nso [mo-hohoro mo ho mo ho a-nan ho]. 2PL also 2PL.wash 2PL.POSS.self 2PL.POSS.self PL-foot body 'If I then, your Lord and Teacher, have washed your feet, you also ought to wash one another's feet' (John 13:14, NIV).

In the examples in (13 b \& c) and (14b), both Akuapem and Asante use a reduplicated verb and a reduplicated anaphor to express a reciprocal situation. Fante reduplicates the verb, but not the anaphor, as shown in example (13a). This pattern is consistent in the data I have so far. Consider the next set of examples:

a. Na Moses fi-ir edzi ke-hyia-a n'asew, na o-kotow-ee(Fa.) and Moses go.PST out go.meet.PST 3SG.POSS.in-law and 3SG.bow.PST na o-fe-ew n'ano; na [wo-bisa-bisa-a hon apow mu;]

and 3SG.kiss.PST 3SG.POSS.mouth and 3PL.ask.REDU.PST 3PL.POSS.health

'So Moses went out to meet his father-in-law and bowed down and kissed him. They greeted each other...' (Exodus 18:7, NIV).

b. Na Mose fi-i adi ko-hyia-a n'ase, na o-kotow (Ak.) And Moses go.PST out go.meet.PST 3SG.POSS.in-law and 3SG.bow.PST

no

few n'ano; na [wo-kyia-kyia-a

3SG.OBJ kiss.PST 3SG.POSS.mouth and 3PL.greet.REDU.PST

won ho won ho] ...

3PL.POSS.self 3PL.POSS.self

'So Moses went out to meet his father-in-law and bowed down and kissed him. They greeted each other ...' (Exodus 18:7, NIV). 
c. Na Mose fi-i adi ko-hyia-a n'ase, na o-kotow (As.) And Moses go.PST out go.meet.PST 3SG.POSS.in-law and 3SG.bow.PST

$\begin{array}{llll}\text { no fe-e n'ano; } & \text { na } & \text { [wo-kyea-kyea-a } \\ \text { 3SG.OBJ kiss.PST } & \text { 3SG.POSS.mouth and } & \text { 3PL.greet.REDU.PST } \\ \text { won ho } & \text { won ho ]... } & \\ \text { 3PL.POSS.self } & \text { 3PL.POSS.self } & \end{array}$

'So Moses went out to meet his father-in-law and bowed down and kissed him. They greeted each other ...' (Exodus 18:7, NIV).

The reciprocal meaning in all these examples cannot be disputed and this has to do with the nature of verbs used. In the real world one does not greet himself/herself or ask himself/herself, "How are you?" We assume that "Moses greeted his father-in-law" and "Moses' father-in-law greeted Moses" is the intended meaning.

Once again, Patience Obeng (personal communication) informs me that constructions in which both the verb and the anaphor are reduplicated to express reciprocity occur in the speech of Fante speakers. She asserts that a sentence like: Hom ndodo homho "Love each other/one another" is perfectly acceptable. This means, therefore, that it is not only the Twi dialects which permit the reduplication of both the verb and the anaphor and this leads me to make the third general statement about reciprocal constructions as follows:

(16) A reciprocal situation is expressed by using a reduplicated verb which selects a reduplicated anaphor as its object/complement.

\subsubsection{Use of a Reduplicated Verb and an Anaphor + quantifier}

The fourth strategy that can be deduced from the data is the use of an anaphor plus the quantifier nkorkor "one-one" with the reduplicated verb. This strategy appears to be more prevalent in Fante. Consider the following examples:

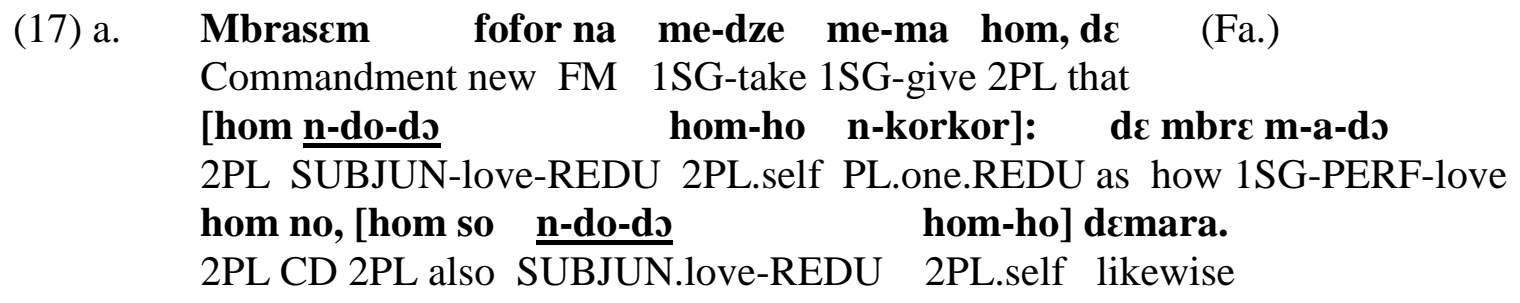


'A new commandment I give to you, that you love one another: just as I have loved you, you also are to love one another' (John 13:34, NIV).

b. Ahyede foforo na me-ma mo, se (Ak. \& As.)

Commandment new FM 1SG-give 2PL that

[mo-n-no-do mo ho] scnea me-do-s mo no,

2PL-SUBJUN-love.REDU 2PL self as 1SG-love-PST 2PL CD

SE [mo nso mo-n-no-do mo ho mo ho!]

so 2PL also 2PL-SUBJUN-love-REDU 2PL.self 2PL.self

'A new commandment I give to you, that you love one another: just as I have loved you, you also are to love one another' (John 13:34, NIV).

The Fante example in (17a) is a complex sentence which contains two reciprocal constructions as indicated by the square brackets. The first one, hom ndodo homho nkorkor "love one another" shows that Fante optionally adds a reduplicated quantifier nkornkor "one-one" to the anaphor. The second reciprocal construction, hom so ndodo homho "you are also to love one another" does not have the quantifier as shown in the first one. It is interesting to see that in the same complex sentence involving two reciprocal constructions, two strategies, i) one in which the plural anaphor is modified by a reduplicated quantifier, and ii) another in which the plural quantifier is not modified by a plural quantifier. In other words, the quantifier is optional and this suggests that the two structures are used interchangeably.

The Twi example in (17b) also presents an interesting situation. Again, there are two reciprocal constructions in this complex sentence. The first one, monnodo mo ho "love one another," has a reduplicated verb followed by an unreduplicated anaphor. The second construction, mo nso monnods mo ho mo ho "you are also to love one another" has both a reduplicated verb and a reduplicated anaphor. It means that in the same complex sentence, two of the options that we have discussed have been utilized to indicate reciprocity.

(18a) below provides an additional example of the Fante use of the anaphor plus a reduplicated quantifier/numeral n-korkor "one-one" (cf. English each other, one another) to indicate reciprocity. In this example, an adverb yie "well" intervenes between the anaphor and the quantifier. The Twi version in (18b) does not have the quantifier.

a. Ennuado mu a, [hom $\underline{\text { n-do-do }}$
Brotherly love in COND 2 PL SUBJUN-love-REDU
$\underline{\text { homho yie nkorkor] }}, \quad$ enyidzi mu a,


2PL.self well PL.one.REDU respectful in

\begin{tabular}{|c|c|c|}
\hline [hom & kan n-dzi-dzi & hom-ho \\
\hline
\end{tabular}

'Be devoted to one another in brotherly love. Honour one another above yourselves' (Romans 12:10, NIV).

b. Mo-m-fa onuado n-no-do mo ho yiye, (Ak., As.) 2PL-SUBJUN-take brotherly love SUBJUN-love-REDU 2PL self well

mu-n-ni kan

n-nidi

mo ho ni.

2PL-SUBJUN-take lead SUBJUN-show-REDU 2PL self respect

'Be devoted to one another in brotherly love. Honour one another above yourselves' (Romans 12:10, NIV).

In all the examples I have gathered so far, wherever the Twi dialects use either the reduplicated verb as in (15b) or a reduplicated anaphor (14b), Fante uses the anaphor + nkorkor construction as in (14a and 15a). It seems to me that the idea of reciprocity is unequivocally expressed with the use of nkornkor "one-one."

Though the optional use of the quantifier is not found in the Twi examples in (16b and 17b), it appears the strategy is not peculiar to Fante alone. Kofi Agyekum (personal communication) informs me that constructions like mondodo mo ho baako baako "love one another (one-one)" occurs in the Twi dialects as well. It means, therefore, that both Fante and the Twi dialects use this strategy to express reciprocal relations and it leads me to make a final general statement about reciprocal constructions in Akan:

(18) A reciprocal situation is expressed by using a reduplicated verb which selects an anaphor plus a reduplicated quantifier nkorkor $(F a$.)/ baako baako (Ak. \& As.) as its object/complement.

Table 1 summarises the strategies for expressing reciprocity in Akan. 
Table 1: Strategies for Coding Reciprocal Relations in Akan

\begin{tabular}{|c|c|c|c|c|}
\hline & $\begin{array}{c}\text { Reduplicated } \\
\text { Verb + plural } \\
\text { Anaphor }\end{array}$ & $\begin{array}{c}\text { Unreduplicated } \\
\text { Verb + } \\
\text { Reduplicated } \\
\text { Anaphor }\end{array}$ & $\begin{array}{c}\text { Reduplicated } \\
\text { Verb }+ \\
\text { Reduplicated } \\
\text { Anaphor }\end{array}$ & $\begin{array}{c}\text { Reduplicated } \\
\text { Verb + } \\
\text { Anaphor }+ \\
\text { Reduplicated } \\
\text { Quantifier }\end{array}$ \\
\hline Fante & + & + & + & + \\
\hline Akuapem & + & + & + & + \\
\hline Asante & + & + & + & + \\
\hline
\end{tabular}

\section{Conclusion}

This paper has shown that reciprocal relations are expressed in Akan transitive constructions involving the use of a possessive pronoun + ho structure in object position. These constructions are made up of:

i) a reduplicated verb and a plural anaphor which is a possessive pronoun plus ho "self"/ "body" construction (the same as what is used for reflexives),

ii) unreduplicated verb and reduplicated anaphor,

iii) a reduplicated verb and a reduplicated anaphor,

iv) a reduplicated verb and a plural anaphor plus the reduplicated quantifier nkorkor (Fa.)/ baako baako (Ak. \& As.).

From what has been outlined above, it emerges that Akan utilizes at least four strategies in expressing reciprocal relations. These strategies involve either reduplicating the verb or the anaphor or both. The only differences between Fante on one hand, and the Twi dialects have to do with dialectal differences in vocabulary.

It must be noted that in all cases, the reciprocal anaphor agrees with its antecedent in being plural. 
Saah: The Syntax of Reciprocal Constructions in Akan

\section{List of abbreviations}

1, 2, 3 first, second, third person

CM: clausal marker

COND: conditional

DEF: definite

FUT: future

NEG: negation marker

NIV: New International Version of the Holy Bible

PERF: perfective

PL: plural

POSS: possessive marker

PRES: present

PROG: progressive

PST: past

REDU: reduplication

SG: singular

SUBJUN: subjunctive

TSRM: temporal switch reference marker 


\section{References}

Ayeh, E. O. 1978. Mmerehua. Accra: Ghana Publishing Corporation.

Bible Society of Ghana. 2012. Kyercw Kronkron (Akuapem Twi). Accra: Bible Society of Ghana.

Bible Society of Ghana. 2012. Twere Kronkron (Asante Twi). Accra: Bible Society of Ghana.

Bible Society of Ghana. 2015. Nwoma Kronkron (Fante). Accra: Bible Society of Ghana.

Boadi, L.A. 2008. "Tense, aspect and mood in Akan." In Aspect and modality in Kwa, edited by F. Ameka and M.E. Kropp-Dakubu, 9-68. Amsterdam: Benjamins.

Chinebuah, Isaac K. 1976. "Reciprocal Clauses in Nzema." In Transactions of the Linguistic Circle of Accra, Vol. 3, edited by H.M.J. Trutenau, 11-34. Basel: Basler Afrika Bibliographien.

Clements, George N. 1982. “Temporal Switch-reference in Akan.” Unpublished Harvard University manuscript (draft version).

Evans, Nicholas. 2008. "Reciprocal Constructions: Towards a Structural Typology." In Reciprocity and reflexivity - description, typology and theory, edited by König, Ekkehard and Volker Gast, 33-104. Berlin: Walter de Gruyter.

Evans, Nicholas, Alice Gaby, and Rachel Nordlinger. 2007. "Valency and reciprocity in Australian languages." Linguistic Typology 11, 541-597.

Haspelmath, Martin and The APiCS Consortium. 2013. "Reciprocal Constructions." In The Atlas of Pidgin and Creole Language Structure, edited by Susanne M. Michealis, Phillippe Maurer, Martin Haspelmath and Magnus Huber, chapter 8, 354-357. Oxford: Oxford University Press.

Kandybowicz, Jason. 2015. "On prosodic vacuity and verbal resumption in Asante Twi." Linguistic Inquiry 46(2): 243-272.

König, Ekkehard and Volker Gast. 2008. Reciprocity and reflexivity-description, typology and theory. Berlin: Walter de Gruyter.

Majid, Asifa, Nicholas Evans, Alice Gaby and Stephen C. Levinson. 2011. "The grammar of exchange: A comparative study of reciprocal constructions across languages." Frontiers in Psychology 2, 34. http://doi.org/10.3389/fpsyg.2011.00034.

Maslova, Elena. 2007. "Reciprocal and Polyadic (Remarkable Reciprocals in Bantu)." In Typology of reciprocal constructions, edited by V.P. Nedjalkov, 335-352. Amsterdam / Philadelphia: John Benjamins Publishing. 
Nishigauchi, Taisuke. 2017. "Syntax of Reciprocals in Japanese." Journal of East Asian Linguistics 1(2): 157-196. New York: Springer: http://www.jstor.org/stable/20100615

Accessed: 10-11-2017 09:50 UTC

Okeke, Chukwuma O. 2008. "Reflexivization and Reciprocality in Igbo." Journal of the Linguistic Association of Nigeria 11, 185-197

Osam, Kweku. 2002. "Reflexive Marking and Related Functions." Journal of Asian and African Studies 64:141-151.

Otoo, Ruby. 2016. "Reflexives and Reciprocal Relations in Ga." Advances in Social Sciences Research Journal 3 (11): 141-153.

Owusu, J. N. 1991. Jkrabiri. $2^{\text {nd }}$ edition. Accra: Bureau of Ghana Languages.

Saah, Kofi K. 2003. Locality and Reflexive Interpretation in Akan. Ms. Department of Linguistics, University of Ghana, Legon, March 12, 2003. 1992. "Null Object Constructions in Akan." MIT Working Papers in Linguistics 17: 219-244. .1989. "Reflexivization in Akan." Journal of West African Languages XIX (2): 15-28.

Safir, Ken and Naga Selvanathan. 2016. "Niger-Congo transitive reciprocal constructions and polysemy with reflexives." In Diversity in African languages, edited by Doris L. Payne, Sara Pacchiarotti and Mokaya Bosire, 495-512. Berlin: Language Sciences Press.

Sung, Li-May. 2006. "Verbal Reflexives/Reciprocals in (Some) Formosan Languages." A Paper presented at Tenth International Conference on Austronesian Linguistics, 17-20 January 2006. Puerto Princesa City, Palawan, Philippines. http://www.sil.org/asia/philippines/ical/papers.html.

Swartz, Anne. Reciprocals in Gur languages. http://languagelink.let.uu.nl/burs/RCL07/pages/abstracts/schwarz.pdf 